\title{
ABNORMALITIES IN MECONIUM OF THE FOETUS AND NEWBORN*
}

\author{
BY \\ JOHN L. EMERY \\ From the Department of Pathology, Children's Hospital, Sheffield
}

Aristotle apparently was the first to give the name 'meconium' to the intestinal contents of the foetus. The word 'mecon-arion' means 'from poppy', or 'like opium', suggesting that the ancients believed it to be the substance maintaining the foetus asleep in the uterus!

Meconium has interested people for a long time (Davy, 1844; Hymanson and Kahn, 1919), but it is only recently when serologists have sought blood group substances in the mucopolysaccharides of meconium that it has been subjected to serious chemical study. Meconium is a large mass of mucus consisting basically of water, muco-proteins and mucopolysaccharides (Rapoport and Buchanan, 1950; Buchanan and Rapoport, 1952). This gives it its general physical properties which are more allied to that of plastic substances than to true simple or colloidal solutions. Biliverdin gives meconium its green colour. There are a number of chemical constituents: fats, steroids, urea, enzymes and sugars (Feldman, 1920). In addition it contains 'meconium bodies', light yellow masses, and organized material in the form of keratinized and nucleated squames.

The purpose of this paper is to draw attention to some changes in the physical properties of meconium apart from meconium ileus, which are of clinical importance. The clinical aspects of many of the cases from which the material for this study was made are described by Zachary (1957) in the next article.

\section{Keratinized and Nucleated Squames and Lanugo Hairs}

Lanugo hairs are usually so scanty as to be of no importance. Nucleated squames and epithelial cells usually occur in small numbers and in the upper small bowel chiefly. We have seen no large masses of such cells.

Normal meconium contains a very variable

* A paper read at the meeting of the British Association of Paediatric Surgeons in London in July, 1956. number of keratinized epithelial squames (Emery, 1952) which are apparently derived from the infant's skin, ingested by way of the amniotic fluid and passed through the whole length of the child's intestine.

This constituent has been used in 'Farber's test' (Farber, 1933) as a means of verifying the patency of the infant's intestinal tract. The squames are usually fairly evenly dispersed in the meconium, but not infrequently are seen in sections to be in dense whirled masses; such masses are usually somewhat paler to the naked eye than the surrounding meconium. Digonnet and Fèvre (1943) consider that these epithelial masses may cause obstruction, but these whirls have never, in our experience, been large enough or firm enough to cause any gross intestinal disturbance. On the other hand we have seen such masses apparently obstructing small air vessels in the lung.

\section{Ano-Rectal Plugs}

Meconium is usually uniformly bile-stained and a deep green, but in infants with any type of obstruction masses of white mucus are common, particularly in the large bowel. The small masses of 'rabbit dropping' stools of small bowel atresia are usually covered with white mucus.

The terminal mass of meconium in the rectum and anus has a pale, unpigmented cap. This, the 'mekonium pfropf' of German writers (Cramer, 1900; Weil, 1902), was apparently first described by Ceranus of Ephesus, and is also mentioned by Aristotle (Mardner, 1909). As Weil (1902) pointed out, the 'mekonium pfropf' does not contain lanugo hairs and keratinized epithelial cells, i.e., it appears to be entirely of intestinal origin. The ano-rectal plug was formerly thought to be of medico-legal importance in the diagnosis of live and still birth, but Cramer (1900) found that in a series of 50 normal infants, 31 had passed this meconium plug before birth. He considered that the plug arose from that 
part of the intestinal tract, normally the colon and rectum, in which bile is not secreted.

One of the earliest reported cases of intestinal obstruction (Berti, 1898) was found plugged by a 'meconium worm', thought to be produced by inflammatory change. Falls and Jaffe (1931) in a survey found ano-rectal plugs in approximately $1 \%$ of all newborn babies, and they considered that in one-fifth of these, i.e., one in 500 infants, this plug caused persistent obstruction, leading to death.

This terminal ano-rectal plug differs from the rest of the meconium, in that it is frequently firmer, and, after fixation in formalin becomes hard, apparently due to its relatively high protein content, and similar to the meconium of meconium ileus. In the uterus, peristaltic action appears to occur in the small intestine, but the expulsive action of the rectum and anus is completely inactive. The ano-rectal plugs are certainly related to difficulty in the commencement of bowel action in the newborn, but it is not certain whether the plugs themselves cause the difficulty, or if in such cases there is a delay in the starting of the expulsive action of the large bowel and rectum. Fleury (1952).considers that these cases can respond to prostigmine.

Fig. 1 illustrates an anal meconium plug passed by an infant aged 2 days, and Fig. 2 a plug in situ from a child who died with intestinal obstruction and in whom no anatomical cause of obstruction was found.

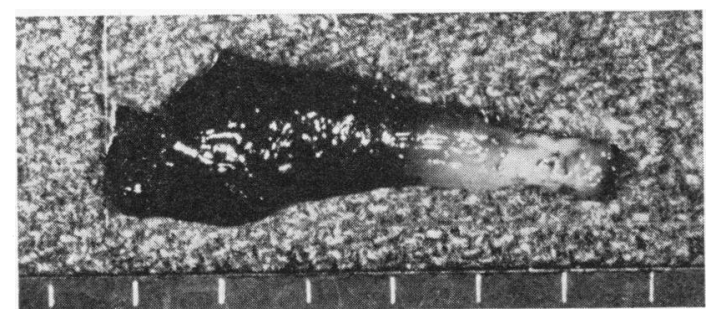

FIG. 1.-Ano-rectal plug from a child who had not passed meconium for two days after birth. This is an ano-rectal plug indistinguishable from a normal plug, the pale end being that adjacent to the anus.

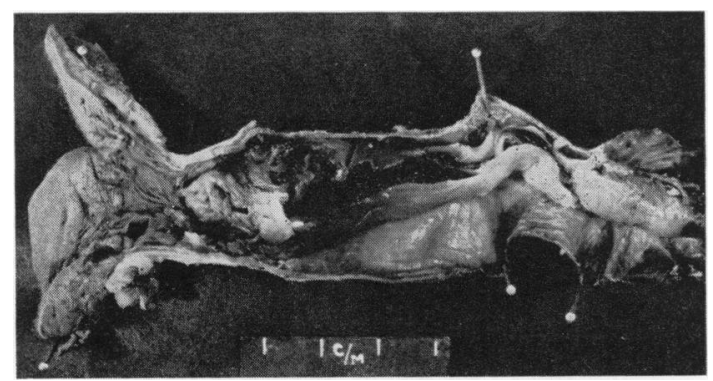

FIG. 2.-Ano-rectal plug from a child dying with intestinal obstruction. The pancreas in this child was completely normal, and no other cause for the intestinal obstruction was found, other than this mass in the colon and rectum.
Meconium Plugs Elsewhere in the Intestine

An occasional finding at routine necropsy on stillborn infants is a segment of partial obstruction in the intestine. In a series of approximately 800 such necropsies we have seen three in the small intestine and one in the large intestine. The obstruction appears to be due to a segment of firm tenacious meconium, forming the tip of a cone at the obstructing point. Fig. 3 shows the external appearance of an obstructed segment in the small intestine. Opened,

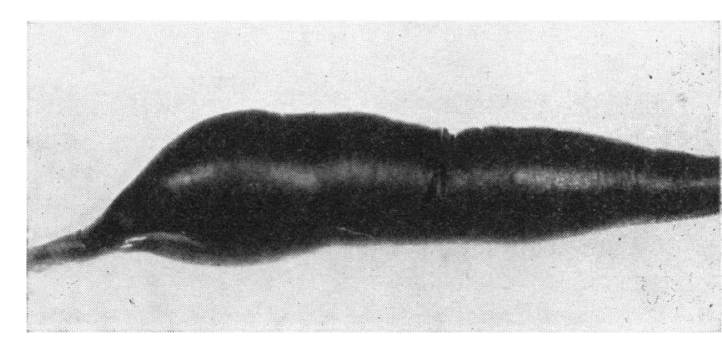

FIG. 3.-Segment of small intestine from a child dying during delivery. The tenacious plug of meconium is in the rapidly narrowing segment adjacent to the area of widest diameter.

this bowel contained normally pigmented meconium, that at the proximal end being thin and fluid as normal meconium. The tryptic activity of the meconium was the same and normal at both the obstructing and the proximal end. The viscidity of the end plug as measured by the surface tension method showed a viscidity as high or higher than that found in meconium ileus. The water content of this obstructing plug was extremely low $(57 \%$, normal $75-85 \%)$. Fig. 4 shows the water and surface tension findings in this case, and the marked inverse relationship between the water content and viscidity of meconium
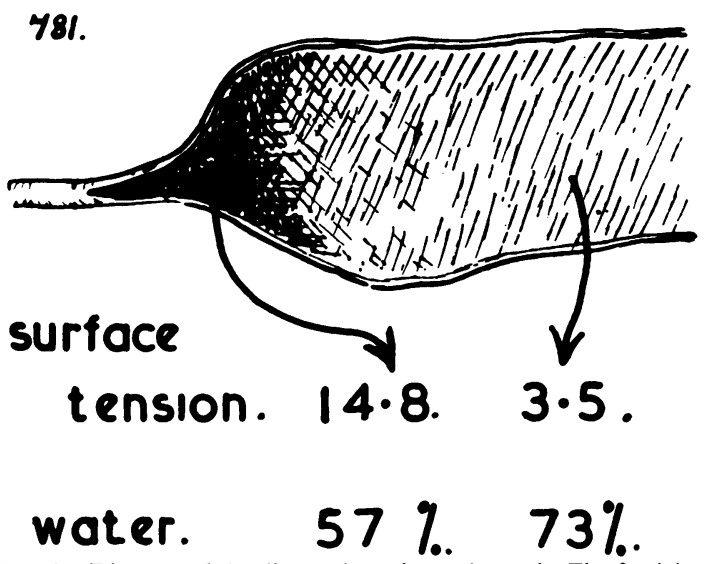

FIG. 4.-Diagram of the dissected specimen shown in Fig. 3, giving the surface tension measurements of the meconium and the water content as taken from the inspissated plug and the relatively normal meconium adjacent. 
that occurs even in normal meconium (Emery, 1954).

The pancreas in these cases appeared to be completely normal and no abnormality could be found in the intestinal neural plexus. We have not seen a death due to this type of meconium plug at necropsy, but from the clinical histories of some children (Zachary, 1957, case 3) in whom there was temporary intestinal obstruction after normal meconium had been passed, it seems likely that such plugs had been present and active. In two of the cases seen by Falls and Jaffe (1931) there had been a similar history of children previously passing normal meconium before passing an inspissated plug. The cases reported by Ullmann (1894) seem to have been of the same nature.

Burger (1938) reported a child with intestinal obstruction due to a solid mass of meconium in the lower ileum. In this case, the pancreas showed only exaggerated lobulation. $\mathrm{He}$ thought that the tenacity of the meconium may have been due to abnormal resorption of fluid. He refers to two other similar cases that have been reported elsewhere.

The interest of these meconium plugs also lies in their possible connexion with intra-uterine intestinal obstruction and meconium peritonitis (Simpson, 1838; Thelander, 1939; Low, Cooper and Cosby, 1949; Franklin and Hosford, 1952), and also with the cases of what are at first suspected to be meconium ileus, but show none of the other features of the fibrocystic syndrome (Farber, 1944; Shwachman, Pryles and Gross, 1956).

\section{Meconium Bodies}

Within the green fluid mass of meconium there can often be seen a large number of small light yellow particles, usually no greater than a millimetre in diameter (Fig. 5). These 'meconium bodies' have been observed since Aristotle, but no one had put forward an adequate theory of their origin or possible role (Schmidt, 1897; Cramer, 1900).

Our interest in them stems from two observations: first, that occasionally these rather hard yellow bodies can be very large, producing obvious distortion of the intestine (Fig. 6 shows a caecum containing a cluster of very large meconium bodies), and secondly, the occasional finding of what seems to be a similar mass in a small segment of bowel, or in peritoneal tissue in the mass of distorted bowel adjacent to a congenital atresia. While we have seen no case of post-natal death due to these bodies, it remains possible that they are responsible for some cases of intestinal volvulus or obstruction in utero leading to intestinal atresia.

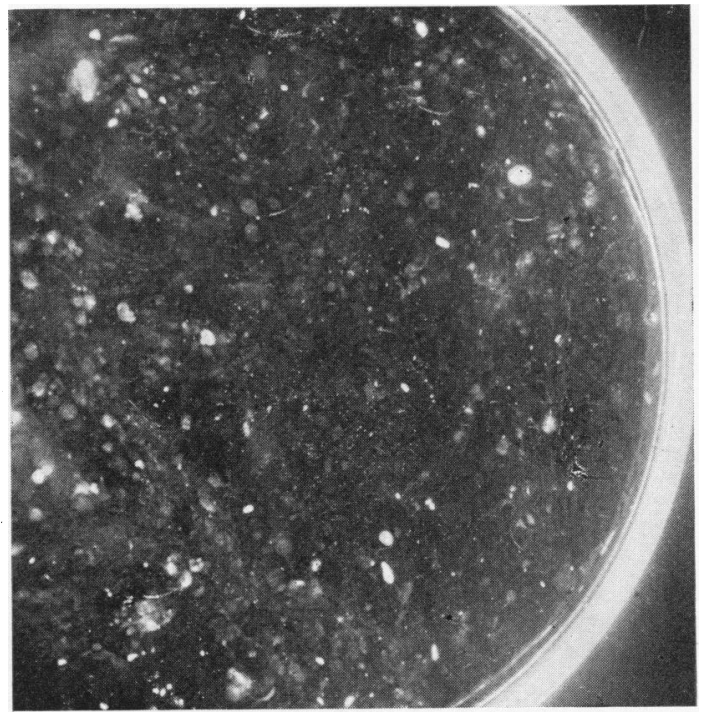

FIG. 5.-Photograph of some meconium lying within a petri dish, showing numerous meconium bodies. Scale approximately $\times 2$.

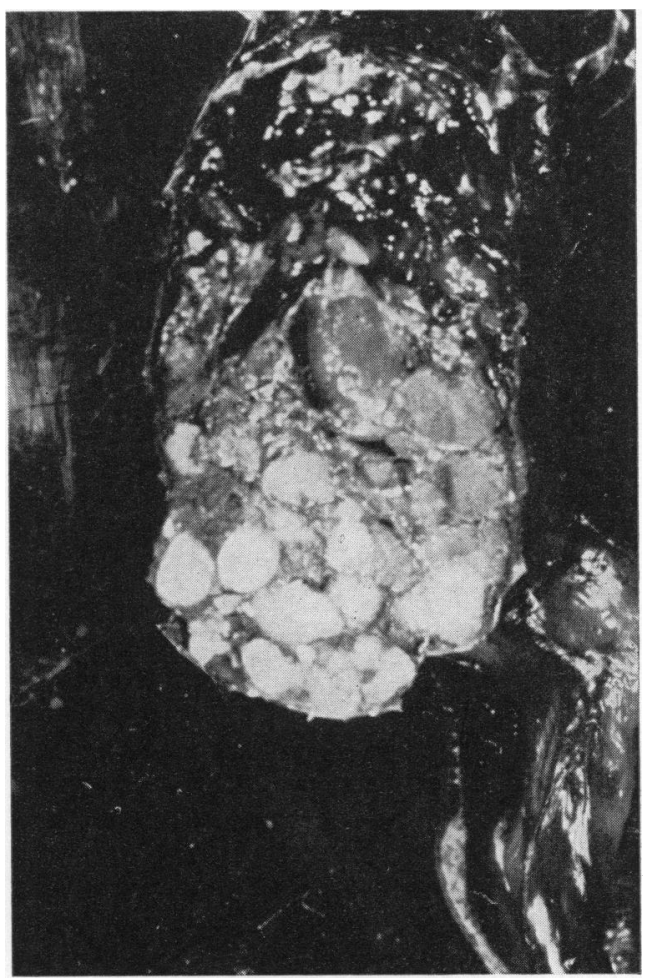

FIG. 6.-Photograph of a caecum containing very large meconium bodies. The ileum and appendix are attached. Scale approximately $\times 1 \frac{1}{2}$ 


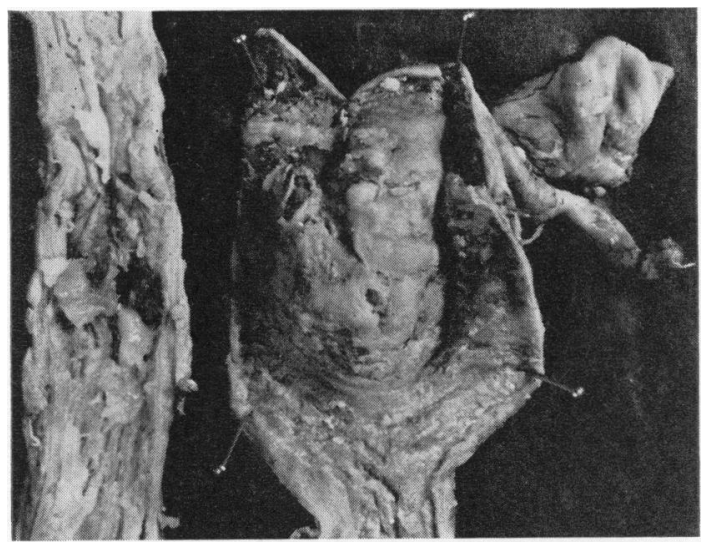

Fig. 7.-Dissected specimen of caecum and descending colon from a child dying with general peritonitis, due to stercoral ulceration. The caecum shows ulceration of the mucosa, and adherent fragments of pale meconium. The narrow segment shows a site of perforation. Scale $\times \frac{8}{4}$.

\section{Colonic Masses Causing Ulceration}

Stercoral ulceration of the colon in the neonatal period is a well-recognized clinical entity. Four cases of spontaneous rupture of the sigmoid in newborn infants without associated intestinal abnormality were reported in 1884 by Zillner. While the majority of such cases are fatal, recoveries are possible by means of a colostomy even in the presence of pneumoperitoneum (Standard, 1952). The perforations may be single, but are frequently multiple, the case reported by Spörlein (1952) having four perforations. The theories of aetiology of these cases have been extremely varied (Standard, 1952): the over-enthusiastic use of enemas, immaturity of the bowel, congenital and acquired diverticula, primary vascular insufficiency, intestinal aplasia, birth trauma (Zillner, 1884) and even foetal enteritis due to the ingestion of infected amniotic fluid (Staemmler, 1953); others refer to intestinal 'dyscrasias' (Fèvre and Duhamel, 1952).

In the four cases of stercoral ulceration that I have examined at necropsy, the most striking features have been pale yellow concretions with overlying bowel wall necrosis and the complete absence of any significant histological abnormality in the bowel wall or pancreas, or any other organ examined. Fig. 7 shows two parts of the same colon from one of these cases; the wide specimen is of the caecum, with the ileum and appendix behind, and this contained a large, pale, friable mass of faeces causing degeneration of the mucosa but no ulceration. The narrow segment shows an ulcerated area in the region of the splenic flexure. These cases all show reactive changes and have been subjected to surgery.

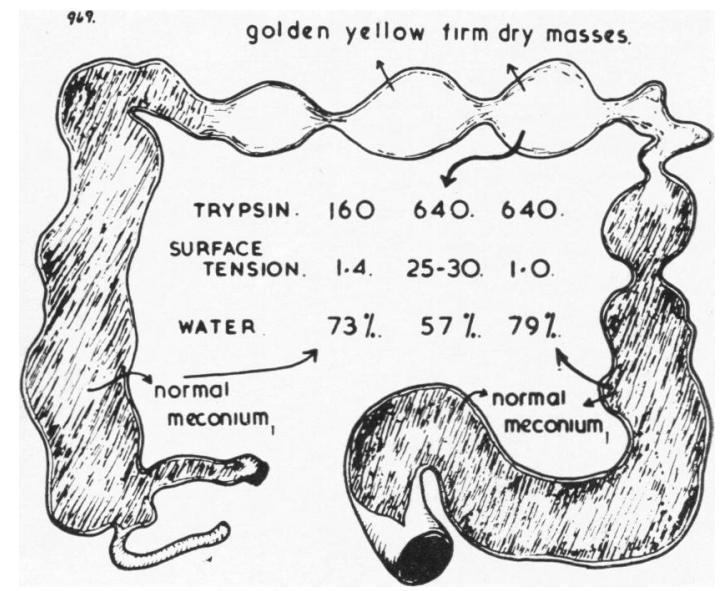

FIG. 8.-Diagram of the large bowel from a stillborn child, showing the position of the masses of inspissated meconium in the transverse colon and splenic flexure, and normal meconium elsewhere in the specimen. The tryptic activity, surface tension and water content

from specimens from the indicated sites shown in the diagram.

It is from the chance finding of similar abnormal bowel contents in a stillborn infant during routine necropsy that an insight into the underlying basic lesion may be obtained. The large bowel of this stillborn child is represented in Fig. 8. The caecum and ascending colon and the lower descending colon, sigmoid and rectum contained apparently normal meconium, but the transverse colon and splenic flexure contained firm yellow masses. The tryptic activity, water content and surface tension of the colonic contents at different levels is shown also in Fig. 8, and this indicates that the meconium is normal in the first and last parts of the bowel, but that the concretions are grossly defective in water content. No gross differences in fat or protein content were detected.

If the case is significant, then it would appear that the neonatal ulceration seen clinically may be due to the abnormal absorption of water in the large bowel, a situation very similar to the localized plugs in the small intestine.

One of the major activities of the large bowel is the absorption of fluid and it seems likely that the faecal impaction may be due to an imbalance between the fluid absorption mechanism and that of propulsion of material along the colon.

\section{Discussion}

The localized abnormalities in meconium discussed above appear to be the effect of local functional abnormalities in the foetal intestine. Because infants that have survived do not appear to be in any way abnormal, it seems that the disorder is one 
related to the peculiar state of apparent suspended animation of the foetal intestine late in pregnancy. There seems to be some alteration in the local water balance between the meconium and the affected segment of bowel that would to some extent explain the changes in physical properties of the meconium. The concentration of epithelial squames in meconium compared with the number present in liquor amnii gives some idea of the vast volume of amniotic fluid that must be swallowed by the foetus and this fluid absorbed through the intestinal wall. The foetal intestinal tract is no passive backwater (Becker, Windle, Barth and Schulz, 1940).

A further point on which we seem to be devoid of knowledge is the stimulation for the altered activity of the child's colonic and rectal activity after birth. Obstetric experience teaches us that a child in 'intrauterine stress' begins passing meconium, but it would be hardly likely that it is simply anoxia that stimulates the bowel.

There appears to be no relationship between intestinal plugs and meconium ileus, for the children do not seem to develop the later fibrocystic picture or to have an abnormal sweating mechanism. The other common disorder of the bowel in the newborn, 'megacolon', is unlikely to be a complete 'all-ornone' disorder, and it is possible that the ano-rectal plug group have some slight variation in normal maturity of the intestinal intramural plexus that our present knowledge does not enable us to recognize.

Perhaps, however, we know no more about the activity of the bowel in the foetus than Hippocrates did when he made the delightful statement 'The presence of excretion in the intestine of the newborn baby proves that the foetus sucks inside the womb'.

\section{Summary}

A group of clinical abnormalities of meconium are described.

It is suggested that the obstructing ano-rectal plug is related to an immaturity of the colonic rectal expulsive mechanism.

Intestinal meconium plugs and stercoral ulceration of the large bowel appear to be related to localized abnormalities in the water balance in the affected segment of bowel.

Much of the material used in this paper came from necropsies that we were able to carry out at the City General Hospital, Sheffield, through the courtesy of Dr. A. J. N. Warrack.

\section{REFERENCES}

Becker, R. F., Windle, W. F., Barth, E. E. and Schulz, M. D. (1940). Surg. Gynec. Obstet., 70, 603 .

Berti, G. (1898). Arch. Kinderheilk., 24, 463.

Buchanan, D. J. and Rapoport, S. (1952). Pediatrics, 9, 304.

Burger, P. (1938). Gynéc. et Obstét., 37, 176.

Cramer, H. (1900). Dtsch. med. Wschr., 26, 194.

Cramer, H. (1900). Dtsch. med. Wschr., 26,194

Digonnet and Fèvre, M. (1943). Mém. Acad. Chir., 69, 297.

Emery, J. L. (1952). Archives of Disease in Childhood, 27, 67.

- (1954). Ibid., 29, 34.

Falls, F. H. and Jaffe, R. H. (1931). Amer. J. Obstet. Gynec. 22, 409.

Farber, S. (1933). J. Amer. med. Ass., 100, 1753.

(1944). J. Pediat., 24, 387.

Feldman, W. M. (1920). The Principles of Ante-natal and Post-natal Child Physiology, pp. 191-3. London.

Fèvre, M. and Duhamel, B. (1952). J. Chir. (Paris), 68, 5.

Fleury, J. (1952). Arch. franc. Pédiat., 9, 725.

Franklin, A. W. and Hosford, J. P. (1952). Brit. med. J., 2, 257.

Hymanson, A. and Kahn, M. (1919). Amer. J. Dis. Child., 17, 112.

Low, J. R., Cooper, G. and Cosby, L. (1949). Surgery, 26, 223.

Low, J. R., Cooper, G. and Cosby, L. (1949). Surge
Mardner, W. (1909). Prag. med. Wschr., 34, 671.

Rapoport, S. and Buchanan, D. J. (1950). Science, 112, 150.

Schmidt, F. C. T. (1897). Vjschr. gerichtl. Med., Ser. 3, 13, 320.

Shwachman, H., Pryles, C. V. and Gross, R. E. (1956). A.M.A. J. Dis. Child., 91, 223.

Spörlein, S. (1952). Arch. Kinderheilk., 144, 63.

Staemmler, M. (1953). Virchows Arch. path. Anat., 323, 143.

Standard, J. E. (1952). Amer. J. Surg., 83, 107.

Thelander, H. E. (1939). Ibid., 58, 371 .

Ullmann, E. (1894). Dtsch. med. Wschr., 20, 37.

Weil, H. (1902). Ibid., 28, 776.

Zachary, R. B. (1957). Archives of Disease in Childhood, 32, 22.

Zillner, E. (1884). Virchows Arch. path. Anat., 96, 307. 